\title{
A Comparative Analysis of Window Width Selection Technique in Data Envelopment Analysis
}

\author{
Ahmad A. Maidamisa \\ Department of Mathematics \\ Universiti Teknologi Malaysia \\ 81310 UTM Johor Bahru
}

\author{
Rohanin Ahmad \\ Department of Mathematics \\ Universiti Teknologi Malaysia \\ 81310 UTM Johor Bahru
}

\author{
Abdul. A. M. Ismail \\ Department of Mathematics \\ Universiti Teknologi Malaysia \\ 81310 UTM Johor Bahru
}

\begin{abstract}
The aim of this paper is to develop a methodology for the selection of window width in Data Envelopment Analysis (DEA). Analytical hierarchal process (AHP) is employed to achieve that purpose. Using panel data, the selected width is experimented with factual data, and results show robustness to efficiency assessment. This paper is the first to use AHP approach in the selection of a window width in DEA window analysis.
\end{abstract}

General Terms: Multi criteria decision Making.

Keywords: Data Envelopment Analysis, Window Analysis, Efficiency.

\section{INTRODUCTION}

In this paper, a DEA window analysis is run in order to obtain the efficiency scores. Charnes et. al [1] first published article on DEA window analysis. The study is to evaluate the capability of 14 US Army recruiting district offices over 7 months. The analytic DEA results disagree substantially depending on whether or not a significant difference at a particular point of time is included in the selected window. For this reason, it was found that the approximation of efficiency in this approach becomes robust by repeatedly moving the window width. The result from window analysis approach is influenced by the selection of window width. That is the number of time periods included in the analysis, of a window, $p$. The width is selected by empirical approach.

When applying DEA, an important rule of thumb is that the number of DMUs is at least twice the sum of the number of inputs and that number plus outputs, otherwise, the model may produce numerous relatively efficient units and decrease discriminating power $[2,3]$. In another development,

Weyman-Jones [4] indicated that as the ratio of the total sum of input and output over the total number of DMU raises the ability of the DEA to be discriminate among the DMU falls significantly, since it becomes likely that any given DMU will find some set of output and input weights, which will make it appears efficient. To resolve this difficulty, DEA window analysis was introduced to increase the number of DMU. This approach makes it feasible to observe how each DMU performs in different periods. Based on these facts, there is a problem. The problem statement is to find a suitable width that is robust to efficiency assessment. As for the selection of window width, is based on Equation (1).

$$
p=\left\{\begin{array}{l}
\frac{k+1}{2}, \text { odd } \\
\frac{k+1}{2} \pm \frac{1}{2}, \text { even }
\end{array}\right.
$$

It can see that if $k$ is an odd number, the selected width turns out to even number. On the other hand, if $k$ is an even number. Then the selected width becomes a continues number. If the latter situation occurs, Charnes [ 5] suggests using both the two values in evaluating DMU. So we can deduce that the window width is selected empirically. In this paper, Analytical Hierarchy Process (AHP) is proposed in the selection of window width.

The structure of the paper is organized as follows. The first section introduces the context of the subject matter. In the second section, a short literature review is provided. In the third section, the methodology adopted is spotlighted. In the fourth section, a window analysis technique is detailed. Lastly, the paper completed with a conclusion.

\section{A LITERATURE REVIEW}

The concept of frontier analysis was first suggested by Farrell [6], subsequently, Charnes [7] started the recent series of discussions. Window analysis is a DEA extended method for monitoring, planning, and improving productivity. It has been successfully applied to evaluate the performance DMUs in a number of situations to mention a few. Charnes [1] selected a window width of 3 , and the maximum number of different DMU is 224. The width that corresponds to this maximum is 4. Therefore, it was arbitrary selected. Hartman [8] applied DEA window analysis to estimate the performance 12 Swedish bank over 1984 to 1992 . Window width 3 was used in the study, while width 4 corresponds to the maximum number. The result shows that smaller bank outperform the larger banks.

Itoh [9] utilizes DEA window analysis to assess eight major container ports in Japan over 1990 to 1999. The window widths selected are 5 and 6 in accordance with the maximum cross references DMU. Reisman [10] examined the influence of deregulation on the efficiency of 11 Tunisian commercial banks during 1990 to 2001. The window width used is 3, while the width that corresponds to the maximum DMU is 6 and 7. Webb [11] applies DEA window analysis method to study the relative efficiency levels of large UK retail banks during 1982 to 1995 . The window width selected is 3. The selection is arbitrarily.

Avkiran [12] applied DEA window analysis to evaluate the performance of 10 Australian commercial banks over 1986 to 1995. The number of period selected for the study is 3 . The 
chosen width does not correspond to the maximum number of cross reference group. The result shows that smaller bank outperform the larger banks. Cullinane [13] utilizes DEA window analysis approach to assess the performance of 25 world major seaports over 1992 to 1999 . The results suggest that estimates of container port efficiency fluctuate over time. The size of the selected width is three years. Sufian [14] used window analysis to examine the long-term trend in efficiency changes of 8 Malaysian commercial banks over 1992 to 2003. Three-year period is selected for the analysis. The selection is the base on trial and error.

Sufian [15] employed DEA window analysis to analyses the long-term trend in efficiency changes of six Singapore commercial banks during the period of 1993 to 2003 . Threeyear window width is selected. In this analysis, the selected width is three years. The selection was based on subjective judgment. Al-Eraqi [16] employed DEA window analysis technique to evaluate the efficiency of 22 cargo seaports in East Africa and Middle East for the period of 2000 to 2005. Four years is chosen as the time period of the analysis. There is no rule for the selection. Pulina [17] employed DEA window analysis to measure the efficiency of hotels across 20 regions in Italy over the period 2002 to 2005 . The number of time period used in the analysis is two years. This selection is based on empirical approach. Results have shown that one out of 20 regions one has fallen short behind. Carbone [18] has shown how DEA window analysis was used to identify efficiency trends over time for a semiconductor manufacturer. Sufian [19] used DEA window analysis to evaluate performance trends of Singapore Commercial Banks over 1993-2003. The result reveals that smaller banks outperform larger banks. Keh [20] employed DEA window analysis from 1999 to 2000 to examine the relationship between efficiency, effectiveness and productivity of marketing expenses; to this aim, 49 DMUs were run. Ross [21] used DEA window analysis to evaluate and identify performance trends of distribution centres over four years. Min [22] formulate and compare a variable return to scale and constant return to scale model to measure the efficiency of six Korean luxury hotel from 2001 to 2003 .

\section{BASIC DEA MODEL}

In the DEA literature, two principal models are viewed. First is the CCR model Charnes [5] that assumes that all DMUs are operating at CRS. Second is the BCC model Banker [24] that hypothesizes VRS. Consider the set of $n$ DMUs. For $D M U_{0}$ under evaluation, let $y_{r 0} \quad(r=1, \ldots, s)$ denote the level of $r^{t h}$ output, and $x_{i 0} \quad(i=1, \ldots, m)$ the level of the $i^{t h}$ inputs. To measure the efficiency of $D M U_{0}$, Charnes [7] proposed the following model.

$\min \theta=\theta^{*}$

Window analysis evaluates a DMU with a cross reference to other DMUs performing in different time periods. It extends the context of evaluation and expands the size of the reference group. One of the biggest advantages of window analysis is that it enhances the discriminating power of DEA by increasing the size of DMUs. To illustrate, from Table 1 below the first window incorporates years 2003, 2004, 2005, and 2006. When a new period is introduced into the window, the earliest period is dropped. In window two, year 2003 will be dropped, and year 2007 will be added to the window. Subsequently, in window 3, years 2005, 2006, 2007 and 2008 will be assessed. The analysis is performed until window 4 analyses years 2006, 2007, 2008 and 2009. As DEA window analysis treats a DMU as a different entity in each year, a four-year window with three DMU is equivalent to 12 DMUs.
Asmild [2] employed DEA window analysis with Malmquist index to evaluate the productivity of five Canadian banks from 1981-2000. The sizes of these banks were expanded to 400 DMUs. In doing so, this will facilitate performance comparison of these banks over time. The number of time period selected is five years, if a different period is selected the result would likely be dissimilar. It was pointed out that the selection of window width should be as small as possible to minimize the unfairness comparison over time, but still large enough to have a sufficient sample size. Results from this study have shown stable performance. Neves [23] assess a sample of 83 firms at a worldwide level in the years 20002002. Two main findings emerge from this analytical thinking. First, the scale efficiency score is higher than the pure technical efficiency score. This indicates that companies' managers should concentrate on productivity improvements. Secondly, the majority of the firms denote decreasing returns to scale (DRS). This result is consistent with an underutilization of capacity and low occupancy rates. Yang [3] measure the productivity of three telecommunications firms in Taiwan from 2001 to 2005 . DEA window analysis approach was used the size of these firm increases to 312 DMUs. This expansion allows us to evaluate the efficiency of large firms over time. The number of time period considered for this study is eight. Results reveals that firm's acquisitions are justified by higher scale size; enlarging a market share to improve financial portfolios help firms to achieve better scale size and government efforts to privatized state-owned companies strengthen competitiveness. However, the width was selected assuming an empirical approach.

This literature review has disclosed that the more recent experimental works mainly concentrate on selection of window width based on empirical approach. In addition to, one of the main shortcomings of recently published works relates to the use of a relatively low number of observations. The present analysis is using roughly 24 observations, stands as a novel example of a panel DEA investigation in analyzing electricity efficiency.

$$
\begin{array}{ll}
\sum_{\mathrm{j}=1}^{\text {subject to }} \\
\sum_{j=1}^{n} \lambda_{\mathrm{j}} \mathrm{x}_{\mathrm{ij}} \leq \theta x_{i 0} & i=1, \ldots, m . \\
y_{r j} \geq y_{r 0}, & r=1, \ldots, s .
\end{array}
$$$$
\lambda_{j} \geq 0, \quad j=1, \ldots, n \text {. } \theta \text {, unrestricted }
$$

\subsection{Empirical Method}

Later, by applying a 4 would considerably increase the number of observation of the sample to 48 providing a greater degree of freedom.

Table 1: Window Breakdown

\begin{tabular}{lr} 
Window 1 & 2003200420052006 \\
Window 2 & 2004200520062007 \\
Window 3 & 2005200620072008 \\
Window 4 & 2006200720082009 \\
\hline
\end{tabular}

A window can be developed in a variety of styles. Prominent among them, is the style developed by Charnes [1], which has 
been successfully employed in previous studies. The method involves is taking the first $p$ time periods out of the total $k$ periods of the evaluation to form the first window, $2, \ldots, p+1$ periods to form the second window, and so on, $p+1 \leq k$. Thus the number of windows is comprised of $w=k-p+1$. In a window, the same DMU, performing at the different periods is treated as if they were a distinctive DMUs performing at the same period. The number of this DMU is $n p$ in each window. The total number of DMUs in the window analysis is $n p w$, instead of $n k$ as observed. The "increased" number of DMUs or the "increased degree of freedom" of the analysis is $n(p-1)(k-p)$. The overlap of consecutive windows is $(p-1)$ periods. This overlapping part facilitates analysis of the data quality and some dynamic property's evaluation. The window analysis provides management with additional information. the average efficiency scores. The variances of efficiency scores. The column average and the column range of the efficiency scores in a single time period for both individual DMUs and the whole set of DMUs. These properties are useful for examining the stability and trend properties of DMUs' performances over time.

DEA Professional version 3.0 Solver software is used to compute the efficiency scores. Cooper [26] suggested a method to design the window length so as to maximize the total number of DMUs, or $n p w$. The selection is based on Equation (1). Applying the concept of maximizing the number of differential DMUs, four years is the recommended window width.

\subsection{Data Sources}

The major sources of data were obtained from a TNB (Tenaga Nasional Berhard) balance sheet and the statistical reports provided by the department of energy commission Suruhayja [25]. These are the inputs' variables.

1. Total Number of Employees (TNE) in thousands.

2. Total length of Transmission and Distribution Cables (TDC) in kilometres, which includes: $66 \mathrm{kv}, 132 \mathrm{kv}, 275 \mathrm{kv}$, $500 \mathrm{kv}$ lines; overhead and underground cables.

3. Total Number of Transmission and Distribution Substations (TDS) in thousands.

while the outputs include:

1. Turnover (TRV) in millions of Malaysian Ringgit.

2. Total Number of Customers (TNC) in thousands, which includes: domestic, commercials, industrial, public lighting, mining and agriculture consumption.

3. Total Unit Sold (TUS) in Gigawatt hours (GWh).

Table 2 shows the descriptive statistics of the data. These include a measure of central tendency and measure of dispersion.

Table 2: Descriptive Statistics of the inputs and outputs

TNE TDC TDS TRV TNC TUS

Max 24,950 723,336 63,237 26,388 7,177443 85,616

$\begin{array}{llllll}\text { Min } \quad 2,024 & 6,792 & 3,201 & 431 & 250,154 & 1,778\end{array}$

Mean 9,365 145,156 20,694 5,917 2,157,818 23,778

SD 10,405.27 216,220.72 22,411.33 7,862.11 2,634,653.66 $30,875.76$

All these inputs and outputs were extracted from Energy Commission's publication except TRV, which was extracted from TNB group Balance sheet Suruhayja [25]. After selecting the inputs and outputs variables, Spearman's correlation coefficient is applied to test whether the variables have an isotonic relationship, i.e. decreasing inputs increase efficiency and increasing outputs increase efficiency as pointed out by Dyson [27]. Table 3 presents the coefficient of correlation. However, one should be cautioned about a result from DEA exhibiting low correlation between inputs Smith [28]. A non parametric statistical test shows that the two corresponding DEA results are highly correlated. This strongly implies that the results are somewhat robust to the selection of inputs and outputs.

Table 3: Spearman Coefficient of Correlation

\begin{tabular}{lllll}
\hline Outputs & & TRV & TNC & TUS \\
\hline Inputs & TNE & 0.9479 & 0.9878 & 0.9748 \\
& TDC & 0.9634 & 0.9337 & 0.9504 \\
& TDS & 0.9830 & 0.9967 & 0.9940
\end{tabular}

\subsection{AHP Based Method}

In the first place, we look at the problem as a selection problem and then look for a suitable method that could solve the problem. The seven-year time period is viewed as decision alternatives, within which we select a particular year. We proposed a Multi Criteria Decision Analysis, particularly AHP to select the best time period. Let: $a_{i}=$ Represent window width $i$. and $w_{i}=$ corresponding weights of $a_{i} i(1,7)$. There are seven time periods, i.e. from 2003 to 2009 every period is representing a decision alternative. Asmild [2], Avkiran [12], Webb [11], Reisman [10], Yang [3] have all suggested that when selecting a window width it should be as small as possible in order to minimize the unfairness when comparing DMUs over time. However, the window width should be large enough to have a sufficient sample size. The following attributes were used.

1. A narrow window width is denoted by NRW.

2. A window width that contains the maximum cross reference DMU is denoted by MCF.

3. An upper bound limit to MCF is denoted by UBL.

4. A lower bound limit to MCF is denoted by LBL.

The following is proposed a narrow window width is very strongly important than the width that contain the largest number of cross reference DMUs.

NRW is moderately to strongly preferred than MCF is accorded the rating $\alpha_{12}=4$.

NRW is moderately to strongly preferred than UBL is accorded the rating $\alpha_{13}=4$.

NRW is extremely preferred than LBL is accorded the rating $\alpha_{14}=9$.

$\mathrm{MCF}$ is equally to moderately preferred than UBL is accorded the rating $\alpha_{23}=2$.

MCF is moderately to strongly preferred than LBL is accorded the rating $\alpha_{24}=4$.

UBL is moderately preferred than LBL is accorded the rating $\alpha_{34}=3$.

Reciprocal element is accorded the rating $\alpha_{j i}=1 / \alpha_{i j}$

All the diagonal elements are equally preferred. $\alpha_{11}=\alpha_{22}=$ $\alpha_{33}=\alpha_{44}=1$.

Hence, the pair wise comparison matrix is shown below:

NRW MCF UBL LBL

$N R W$
$\operatorname{UBF}$
$\operatorname{LBL}$$\left[\begin{array}{llll}\alpha_{11} & \alpha_{12} & \alpha_{13} & \alpha_{14} \\ \alpha_{21} & \alpha_{22} & \alpha_{23} & \alpha_{24} \\ \alpha_{31} & \alpha_{32} & \alpha_{33} & \alpha_{34} \\ \alpha_{41} & \alpha_{42} & \alpha_{43} & \alpha_{44}\end{array}\right]$


The total number of allocation is $n(n-1) / 2$. Reciprocals elements are position appropriately and all diagonal elements assumed unity.

\section{$N R W \quad M C F \quad U B L \quad L B L$}

$N R W$
$M C F$
$U B L$$\left[\begin{array}{cccc}1 & 4 & 4 & 9 \\ 1 / 4 & 1 & 2 & 4 \\ 1 / 4 & 1 / 2 & 1 & 3 \\ 1 / 9 & 1 / 4 & 1 / 3 & 1\end{array}\right]$

The preference matrix serves as input and the outputs are weights (eigenvectors $\bar{w}$ ). Thus

$\bar{w}=\left[\begin{array}{l}w_{N R W} \\ w_{M C F} \\ w_{U B L} \\ w_{L B L}\end{array}\right]=\left[\begin{array}{l}0.5978 \\ 0.2093 \\ 0.1387 \\ 0.0542\end{array}\right]$

$\lambda_{\text {max }}=4.1050$,

$\mathrm{C} \mathrm{I}=0.03500, \mathrm{C} \mathrm{R}=0.03888$.

Let the comparison matrix for the attributes be: $\Phi_{N R W}$ , $\Phi_{M C F}, \Phi_{U B L}, \Phi_{L B L}$. The weight for the first attributes is:

$w_{\Phi_{N R W}}=\left[\begin{array}{l}w_{1} \\ w_{2} \\ w_{3} \\ w_{4} \\ w_{5} \\ w_{6} \\ w_{7}\end{array}\right]=\left[\begin{array}{l}0.092 \\ 0.076 \\ 0.344 \\ 0.172 \\ 0.108 \\ 0.110 \\ 0.099\end{array}\right]$

$\lambda_{\max }=7.413$,

$\mathrm{C} \mathrm{I}=0.069, \mathrm{C} \mathrm{R}=0.052$. Based on the value of CR we accept the pair wise comparison since

$\mathrm{C} R=0.052 \leq 0.100$.

Second attributes:
$w_{\Phi_{M C F}}=\left[\begin{array}{l}w_{1} \\ w_{2} \\ w_{3} \\ w_{4} \\ w_{5} \\ w_{6} \\ w_{7}\end{array}\right]=\left[\begin{array}{l}0.069 \\ 0.074 \\ 0.149 \\ 0.212 \\ 0.207 \\ 0.100 \\ 0.189\end{array}\right]$

$\lambda_{\text {max }}=7.772$,

$\mathrm{C} I=0.129, \mathrm{C} R=0.097$. Based on the value of $\mathrm{CR}$ we accept the pair wise comparison since

$\mathrm{CR}=0.097 \leq 0.100$

Third attributes:

$w_{\Phi_{U B L}}=\left[\begin{array}{c}w_{1} \\ w_{2} \\ w_{3} \\ w_{4} \\ w_{5} \\ w_{6} \\ w_{7}\end{array}\right]=\left[\begin{array}{l}0.082 \\ 0.074 \\ 0.329 \\ 0.168 \\ 0.087 \\ 0.131 \\ 0.189\end{array}\right]$

$\lambda_{\text {max }}=7.748, \mathrm{C} \mathrm{I}=0.125, \mathrm{C} \mathrm{R}=0.094$. Based on the value of $\mathrm{CR}$ we accept the pair wise comparison since $\mathrm{C} \mathrm{R}=$ $0.094 \leq 0.100$. Fourth attributes:

$w_{\Phi_{L B L}}=\left[\begin{array}{l}w_{1} \\ w_{2} \\ w_{3} \\ w_{4} \\ w_{5} \\ w_{6} \\ w_{7}\end{array}\right]=\left[\begin{array}{l}0.063 \\ 0.074 \\ 0.141 \\ 0.202 \\ 0.220 \\ 0.099 \\ 0.201\end{array}\right]$

$\lambda_{\text {max }}=7.567, \mathrm{C} \mathrm{I}=0.094, \mathrm{C} \mathrm{R}=0.072$. Based on the value of $\mathrm{CR}$ we accept the pair wise comparison since $\mathrm{CR}=0.072 \leq 0.100$ 
The resulting set of weights for each of the alternatives with respect to each attributes is presented in the following matrix below:

\begin{tabular}{|c|c|c|c|c|c|c|c|}
\hline$a_{1}$ & 2 & & $x_{4}$ & $a_{5}$ & $a_{6}$ & $a_{7}$ & \\
\hline$N R W$ & {$[0.092$} & 0.076 & 0.344 & 0.172 & 0.108 & 0.110 & 0.099 \\
\hline$M C F$ & 0.069 & 0.074 & 0.149 & 0.212 & 0.207 & 0.100 & 0.189 \\
\hline$U B L$ & 0.082 & 0.074 & 0.329 & 0.168 & 0.087 & 0.131 & 0.189 \\
\hline$L B L$ & 0.063 & 0.074 & 0.141 & 0.202 & 0.220 & 0.099 & 0.201 \\
\hline
\end{tabular}

Finally, the ranking of the width to be made for each attributes are found by determining the product of the attributes priorities and the weights as shown below:

\begin{tabular}{|c|c|c|c|c|c|c|c|c|}
\hline & \multicolumn{2}{|c|}{ NRW } & \multicolumn{2}{|c|}{$M C F$} & \multicolumn{2}{|c|}{$U B C$} & $\angle B I$ & $\%$ \\
\hline$a_{1}$ & {$[0.092]$} & & 0.069 & & 0.082 & & {$[0.063]$} & 08.48 \\
\hline$a_{2}$ & 0.076 & & 0.074 & & 0.074 & & 0.074 & 07.52 \\
\hline$a_{3}$ & 0.344 & & 0.149 & & 0.329 & & 0.141 & 29.01 \\
\hline$a_{4}=0.598$ & 0.172 & +0.209 & 0.212 & +0.139 & 0.168 & +0.054 & 0.202 & $=18.14$ \\
\hline$a_{5}$ & 0.108 & & 0.207 & & 0.087 & & 0.220 & 13.19 \\
\hline$a_{6}$ & 0.110 & & 0.100 & & 0.131 & & 0.099 & 11.02 \\
\hline$a_{7}$ & 0.099 & & 0.189 & & 0.189 & & 0.201 & 13.58 \\
\hline
\end{tabular}

From the above discussion we come to the following conclusion. The composite scores indicate that according to realities facing decision makers it is better to select $a_{3}$, because it has the highest ranking of $29.01 \%$ out of $100 \%$. The decision maker goal is to select a width that can give a better comparison.

\subsection{Comparison between Empirical Method and AHP Based Method.}

If we look at Table 5, we see that under TNB, the fourth window develops a very low variance of TE3, when AHP based method is put into use, while empirical method yields a low variance of TE4. This gives ample evidence that AHP based method is superior to empirical method. Another evidence is found in the first and second window of SESB and SESCO. The first window of SESB show very low variance of TE3 when AHP based method is applied, but a different result is obtained if empirical method is employed. This gives rise to a high variance of TE4. Likewise, in SESCO's appraisal, AHP based method brings out low variances of TE3, whilst empirical method generates high variances of TE4. The second window of SESCO yields results from the two different approaches. When AHP based method is used to appraise SESCO, it brings out medium variance of TE3, on the other hand, when empirical method is employed to evaluate SESCO, it gives rise to a high variance of TE4.

Table 5: Variance of Technical Efficiency

\begin{tabular}{|c|c|c|c|}
\hline WINDOW & $\begin{array}{l}\text { TNB } \\
\text { TE3 TE4 }\end{array}$ & $\begin{array}{c}\text { SESB } \\
\text { TE3 TE4 }\end{array}$ & $\begin{array}{l}\text { SESCO } \\
\text { TE3 TE4 }\end{array}$ \\
\hline 1. & - & Very Low & High Low \\
\hline 2. & - & - & Medium High \\
\hline 3. & - & - & - \\
\hline 4. & Very Low & Low - & - \\
\hline
\end{tabular}

\section{SUMMARY AND CONCLUSION}

The paper used DEA window analysis to evaluate the performances of three Malaysian electric utility firms over the period of seven years period (2003 to 2009). The empirical approach is based on the principle of moving average. It can detect the performance trend of a DMU over time. A DMU in a different period is considered as if it was a different DMU entirely. In doing so, the efficiency score of a DMU in a particular period is put next to its own efficiency score in other periods in addition to the efficiency scores of other DMU. This expands the number of data points in the analysis, which can be useful when dealing with small sample size.

Window analysis technique is employed to compute three economic indicators of this firm. These indicators are technical efficiency score, pure technical efficiency score and scale efficiency score. Technical efficiency is the effectiveness with which a given set of inputs is used to produce outputs. If a firm is producing at maximum output possible given the resources it employs, such as labor and machinery, and the best technology available, it is said to be technically efficient. Pure technical efficiency score measures how a firm utilizes its resources under exogenous environments. Whilst scale efficiency is the ratio of technical efficiency and to pure technical efficiency. There are two possible assumptions while computing efficiency scores in DEA window analysis; these are constant return to scale and variable return to scale. Constant return to scale is held when an increase in all inputs by $1 \%$ result to corresponding increase in all outputs by $1 \%$, while variable return to scale is said to hold when the constant return to scale assumption is not fulfilled. Variable return to scale measures only technical efficiency, while the constant return to scale measures technical efficiency as well as efficiency loss when the firm does not operate in its most productive scale size. 


\section{REFERENCES}

[1] Charnes, A., Clark, A. T., Cooper, W., and Golany, B., 1985a. A Developmental Study of Data Envelopment Analysis in Measuring the Efficiency of Maintenance units in the US Air forces. Annals of Operations Research, 2, 95-112.

[2] Asmild, M., Joseph, C., Vanita, A, and Claire, S., 2004.Combining DEA window analysis with the Malmquist index approach in a study of the Canadian Banking Industry. Journal of Productivity Analysis 21, 67-89.

[3] Yang, H., and Chang, C., 2009.Using DEA Window Analysis to Measure Efficiencies of Taiwan's Integrated Telecommunication firms. Telecommunications Policy, 33, 98-108.

[4] Weyman-Jones, G., 1991. Productive Efficiency in Regulated Industry: The Area Electricity Boards of England and Wales. Energy Economics, 3,116-122.

[5] Charnes, A., Cooper, W., Golany, B., Seiford, L.M., and Stutz, J.1985b. Foundation of Data Envelopment Analysis for Pareto-Koopmans Efficient Empirical Production Functions. Journal of Econometrics. 30, 1-17.

[6] Farrell, M.J., 1957. The Measurement of Productive Efficiency. Journal of Royal Statistical Society, 120(3), 253290.

[7] Charnes, A., Cooper, W., and Rhodes, E. Measuring the Efficiency of Decision Making Units. European Journal of Operations Research, 2(6), 429-444.

[8] Hartman, T., and Storbeck, J., 1996. Input Congestion in Loan Operations. International Journal of Production Economics, 46(7), 413-421.

[9] Itoh, H., 2002. Efficiency Changes at Major Container Ports in Japan: A window Application of Data Envelopment Analysis. In: Conference. RURDS. The Applied Regional Science Conference, Blackwell, UK, 133-154.

[10] Reisman, A., Daouas, M., Oral, M., Rebai, S., and Gatoufi, S. 2003. Impact of Deregulation on Technical and Scale efficiencies of Tunisian Commercial Banks: WindowExtended Data Envelopment Analysis.Techincal Rept. Working Paper. Faculte des sciences Economiques et de Gestion de Tunis Universte El Manar, Tunisie.

[11] Webb, R., 2003. Levels of Efficiency in UK Retails Banks: A DEA Window Analysis. International Journal of Economics and Business, 10(3), 305-322.

[12] Avikiran, N., 2004. Decomposing Technical Efficiency and Window Analysis. Studies in Economics and Finance. 22(1),61-91.

[13] Cullinane, K., Song, D., and Wang, F., 2004. Application of DEA window Analysis to Container Port Production Efficiency. Review of Network Economy, 32, 184-206.

[14] Sufian, F., 2006. Trend in the Efficiency of Publicly listed Malaysian Commercial Banks overtime: A Non Parametric DEA window analysis approach. Banks and Banks System, 1(2), 144-167.
[15] Sufian, F., 2007. Trend in the Efficiency of Singapore's Commercial Banking groups: A Non Stochastic frontier DEA window analysis approach. International Journal of Productivity and Performance Management, 56(2), 99-136.

[16] Al-Eraqi, A., Mustafa, A., and Khader, A. 2010. An Extended DEA Window Analysis: Middle East and East African Seaports. Journal of Economics Studies, 37(2), 208218

[17] Pulina, M., Detotto, C., and Paba, A., 2010. An Investigation into the relationship between size and efficiency of the Scale efficiencies of the Italian Hospitality Sector: A Window DEA approach. European Journal of Operations Research, 204, 613-620.

[18] Carbone, T. D., 2000.Measuring Efficiency of Semiconductor Manufacturing Operations Using Data Envelopment Analysis (DEA). In Conference RWS IEEE/Semi Advanced Semiconductor Manufacturing Conference, Springer, US, 56-62.

[19] Sufian, F., and Majid, M., 2007. Singapore's Banking efficiency and its Relation to stock returns: A DEA window analysis approach. International Journal of Business Studies, 15(1), 83-106.

[20] Keh, T., Chu, S., and Xu, J., 2006. Efficiency, Effectiveness and Productivity of Marketing in Services. European Journal of Operations Research, 170, 265-276.

[21] Ross, A., Droge, C., 2001. An Integrated Benchmarking Approach to Distribution center performance using DEA Modelling. Journal of Operations Management, 20, 19-32.

[22] Min, H., Min, H., and Joo, S., 2008. A Data Envelopment Analysis- Based Balanced Scorecard for Measuring the Comparative Efficiency of Korean Luxury Hotels. International Journal of Quality and Reliability Management, $25,349-365$

[23] Neves, J., and Lourenco, S., 2009. Using Data Envelopment Analysis to select Strategies that improve the performance of Hotels Companies. International Journal of Contemporary Hospitality Management, 21(6), 698-712.

[24] Banker, R.D., Chanes, A., and Cooper, W., 1984. Some Model for Estimating Technical and Scale Inefficiencies in Data Envelopment Analysis. Management Science, 30, 10781092.

[25] Suruhayja, G., 2009. Annual Report, Tenega Nasional Berhad.

[26] Cooper, W., Seiford, L.M., and Tone, K., 2007. Data Envelopment Analysis: A Comprehensive Text with Models Applications, $2^{\text {nd }}$ Edition. Springer Science, New York.

[27] Dyson, R., Allen, R., Camanho, A., Podinovski, V., Sarrico, C., and Shale, E., 2001. Pitfalls and Protocols in DEA. European Journal of Operations Research, 132, 245259.

[28] Smith, P., 1997. Model Misspecification in Data Envelopment Analysis. Annals of Operations Research, 73, 233-252. 